\title{
Burden and quality of life of mothers of children and adolescents with chronic illnesses: an integrative review ${ }^{1}$
}

\author{
Eliza Cristina Macedo ${ }^{2}$ \\ Leila Rangel da Silva ${ }^{3}$ \\ Mirian Santos Paiva ${ }^{4}$ \\ Maria Natália Pereira Ramos ${ }^{5}$
}

Objective: to identify and analyze the evidence available regarding evaluation of burden and quality of life of mothers who are caregivers for children and adolescents with chronic illnesses. Method: an integrative review, undertaken in the electronic sources MEDLINE; Academic Search Premier; CINAHL; LILACS; SciELO and PubMed, between 2010 and 2014. Results: among the 22 documents selected, there was a predominance of convenience samples and non-experimental transversal designs, at the levels IV and III2. The caregiver burden scales used were the Zarit Burden Interview and Montgomery-Borgatta Caregiver Burden Scale-Revised along with the following instruments for evaluating quality of life: The World Health Organization Quality of Life-BREF Scale; Self-report questionnaires; The UIm Quality of Life Inventory for Parents of chronically ill children; Asthma Caregiver Quality of Life Questionnaire; and the Nottingham Health Profile. Quality-of-life appears to be influenced in a complex and interrelated way by the physical and mental health of the mothers who are caregivers, in accordance with their level of independence, social relationships, environment, and the extent to which they see themselves as burdened. Conclusion: the revealing of the results for the evaluation of burden and quality of life of mothers who are caregivers has implications for the planning and implementation of effective interventions, by the multidisciplinary team, if they are to relieve the burden.

Descriptors: Quality of Life; Burden; Caregivers; Child; Adolescent.

\footnotetext{
${ }^{1}$ Supported by Coordenação de Aperfeiçoamento de Pessoal de Nível Superior (CAPES), Brazil, process \# 009610/2014-06.

2 Doctoral student, Universidade Federal do Estado do Rio de Janeiro, Rio de Janeiro, RJ, Brazil. Assistant Professor, Escola de Enfermagem Alfredo Pinto, Universidade Federal do Estado do Rio de Janeiro, Rio de Janeiro, RJ, Brazil. Scholarship holder from Coordenação de Aperfeiçoamento de Pessoal de Nível Superior (CAPES), Brazil.

${ }^{3}$ Post-doctoral fellow, Universidade Federal da Bahia, Salvador, BA, Brazil. Associate Professor, Escola de Enfermagem Alfredo Pinto, Universidade Federal do Estado do Rio de Janeiro, Rio de Janeiro, RJ, Brazil. Scholarship holder from Coordenação de Aperfeiçoamento de Pessoal de Nível Superior (CAPES), Brazil.

${ }^{4} \mathrm{PhD}$, Associate Professor, Universidade Federal da Bahia, Salvador, BA, Brazil.

${ }^{5}$ PhD, Professor, Universidade Aberta de Lisboa, Lisboa, Portugal.
}

Corresponding Author:

Eliza Cristina Macedo

Universidade Federal do Estado do Rio de Janeiro

Rua Xavier Sigaud, 290

Bairro: Urca

CEP 22290-180, Rio de Janeiro, RJ, Brasil

E-mail: macedo.e@oi.com.br
Copyright $\odot 2015$ Revista Latino-Americana de Enfermagem This is an Open Access article distributed under the terms of the Creative Commons Attribution Non-Commercial License (CC BY-NC).

This license lets others distribute, remix, tweak, and build upon your work non-commercially, and although their new works must also acknowledge you and be non-commercial, they don't have to license their derivative works on the same terms. 


\section{Introduction}

The studies undertaken in recent years regarding care in the management of various chronic illnesses in children and adolescents ${ }^{(1-3)}$ indicate that it is the mothers who are the main people involved in the care process.

Important assertions depend on this fact, such as the burden of the mothers who are the caregivers, who in addition to domestic responsibilities undertake complex activities which are not part of their routine, arising from the care for their children with chronic illnesses. Caregiver burden can culminate in acute and chronic physical disorders, resulting in isolation and depression, as well as financial disequilibrium, reduction in libido and self-accusation ${ }^{(4)}$.

The caregiver's burden is defined as objective when it corresponds to the physical and/or mental effects arising from the act of caring; and as subjective when related to the negative sensation which the act of caring provokes in the caregiver(5).

In order to measure the caregiver's level of burden, instruments have been developed for evaluating the variations in the burden of care for different illnesses, translated and validated for various languages ${ }^{(4-7)}$. Among the instruments for evaluating burden which have been validated and adapted for Brazil, emphasis is placed on: the Caregiver Burden Scale ${ }^{(6)}$ and the Zarit Burden Interview ${ }^{(7)}$.

Both these scales have 22 items which measure the level of burden, the first referring to the domains of general tension, isolation, disappointment, emotional involvement and environment ${ }^{(6)}$; while the second refers to the time made available for the care, implications for physical health, social relationships, emotional health and perception of burden ${ }^{(7)}$. The scores are interpreted in the following way: $0-20$, little or no burden; 21 40 , medium to moderate burden; $41-60$, moderate to severe burden; $61-88$, severe burden ${ }^{(6-7)}$.

The decision was made to include those scales for the evaluation of the caregivers whose authors selected the term "sobrecarga", translated from the English word 'burden', although other concepts are verified, such as: stress, tension, psychological suffering, anxiety and depression ${ }^{(4-5)}$.

The elements studied most in relation to the caregivers are emotional and social aspects, family break-up, and the impact of the care ${ }^{(1-3)}$. Although, on the one hand, these women recognize the fundamental role which they perform in the care of their child, on the other, this can affect their quality of life.

The term quality-of-life is consolidated in the Brazilian and international literature as a multidimensional construct, there nevertheless being no consensus regarding its definition. The World Health Organization Quality of Life - WHOQOL group(8), of the World Health Organization (WHO) defines quality of life as "individuals' perception of their position in life in the context of the culture and value systems in which they live and in relation to their goals, expectations, standards and concerns". The evaluation of the quality of life has been the target of multiple areas of knowledge, such as psychology, nursing, medicine, nutrition, pharmacy, speech therapy and physiotherapy, in which generic instruments and specific ones for measurement are used( $^{(9-14)}$

The WHOQOL instruments can be used in their respective cultural validations, and their results may be compared between the various cultures, due to this being a general instrument for measuring quality of life. The abbreviated version, the WHOQOL-BREF, validated in adult populations, includes four domains: physical, psychological, relationships and environment, and is available in more than 40 languages, including Brazilian Portuguese(15).

Another widely-used instrument for evaluating quality of life is the Medical Outcomes Study 36-Item Short-Form Health Survey (SF-36). It is generic and multidimensional, with 36 items separated into eight domains: functional capacity, physical aspects, pain, general health status, vitality, social aspects, emotional aspects and mental health. The scores go from $0=$ worst general health status to $100=$ best health status ${ }^{(16)}$.

Based on this context, the aim is to identify and analyze the evidence available regarding evaluation of burden and quality of life of mothers who are caregivers for children and adolescents with chronic illnesses.

\section{Method}

The integrative literature review brought the researchers closer to the evolution of the issue over recent years. The recommended steps were followed: the establishing of the guiding questions, the definition of the sample, the categorization and evaluation of the studies, the interpretation of the results and the summarizing of the knowledge ${ }^{(17)}$.

The guiding questions proposed are: what are the studies' methodological characteristics, and what are 
their levels of evidence? Which instruments of evaluation of burden and quality of life are used in the studies? How is the quality of life of the mothers who are caregivers changed in the light of the child's chronic condition?

The results described, based in the scientific knowledge and in the clinical practice of professionals from the healthcare area, are increasingly incorporated into the investigations, legitimating the approach termed Evidence-Based Practice (EBP).

The practice of Evidence-Based Nursing consists of summarizing the best scientific evidence, produced with methodological rigor, so as to incorporate it into healthcare practice, forming a basis for decision-making in the various domains of the nurse's work. This means that the elements of the professional's decision-making, which make up this practice, are - besides the scientific findings - the careful analysis of the validity of this information, and of the levels of scientific evidence which it presents ${ }^{(18)}$.

The basis for the classification of the type of evidence of the studies presented in this review is The Brazilian Centre for Evidence-Based Healthcare: an Affiliate Centre of the Joanna Briggs Institute (JBI), which recommends the classification of the evidence obtained in accordance with the following methodological outline:

Level I. Systematic review, containing only randomized controlled clinical trials.

Level II. At least one randomized controlled clinical trial.

Level III 1. Controlled clinical trials, well designed, without randomization.

Level III 2. Well-designed or case control cohort studies, analytical studies, ideally from more than one research center or group.

Level III 3. Multiple time series, with or without intervention and results in noncontrolled experiments.

Level IV. The opinion of respected authorities, based in clinical criteria and experience, descriptive studies or reports from committees of specialists ${ }^{(18)}$.

In order to consider scientific production related to the issue proposed, two independent researchers evaluated the records. As inclusion criteria, the following were defined: international and Brazilian scientific articles, with the descriptors: quality of life, burden, caregivers, child, adolescent, mother, chronic disease, qualidade de vida, carga, cuidadores, criança, adolescente, mãe, doença crônica, published between 2010 and 2014. The exclusion criteria were duplicated studies; the records which did not focus on the child or adolescent as the target of care; those which did not include the mother (biological or adoptive) as the main caregiver; and the studies validating evaluation instruments.

The selection took place through the metasearch engine of the Coordination for the Improvement of Higher Education Personnel (CAPES), using the Boolean operators AND and OR.

The scientific articles were extracted from the electronic sources MEDLINE/BVS (Medical Literature Analysis and Retrieval System Online/Biblioteca Virtual em Saúde); Academic Search Premier; CINAHL (Cumulative Index to Nursing and Allied Heath Literature); LILACS (Latin American and Caribbean Health Sciences Literature database); SciELO (Scientific Electronic Library Online) and PubMed Central (PMC).

The search strategies took place between December 2013 and April 2014, and the main information was extracted from each document selected, in accordance with an instrument elaborated by the authors: identification of the study (source, title, place, authors, date and objectives); methodological design (sample, instruments, method and level of evidence); and critical analysis (result and conclusion).

In the combining of the descriptors, 72 articles were found, investigating the quality of life and burden of caregivers of children and adolescents with chronic physical or mental illnesses. After reading the abstracts and refining the search, 22 articles were selected, which made up the sample, as presented in Table 1.

Table 1 - Distribution of the articles found, excluded and selected, by electronic media. Rio de Janeiro, State of Rio de Janeiro, Brazil, 2014

\begin{tabular}{lccc}
\hline Electronic media & Articles found & Excluded & Selected \\
\hline CINAHL & 8 & 6 & 2 \\
Academic Search & 8 & 7 & 1 \\
Premier & 7 & 6 & 1 \\
MEDLINE & 25 & 17 & 8 \\
PubMed & 11 & 5 & 6 \\
SciELO & 13 & 9 & 4 \\
LILACS & 72 & 50 & 22 \\
Total & & & \\
\hline
\end{tabular}




\section{Results}

The search resulted in 22 articles, distributed in the areas of Psychology (seven), Nursing (six), Medicine (six), Physiotherapy (two) and Social Services (one), in nine different countries: Brazil (10), the United States of America (four), Spain (two), Turkey (one), Sweden (one), Germany (one), the United Kingdom (one), South Korea (one) and Columbia (one).

The objectives in determining the burden and quality of life of the caregivers were presented as associated with the variables related to the caregiver, such as quality of sleep, mental health, stress, anxiety, depressive symptoms, perception of the child's illness, impact of the coping strategies and of self-efficacy, ethnic and regional differences, and sociodemographic data. Variables related to the child or adolescent were also ascertained, such as age, type of pathology, seriousness of the illness and therapeutic interventions.

The chronic illnesses in children or adolescents approached were broncho-pulmonary dysplasia, cerebral palsy, asthma, eating disorders, hemophilia, autism, sickle cell anemia, cancer, myelomeningocele, obesity and inborn errors of metabolism.

The following predominated among the articles obtained: 19 convenience samples, two studies with sample calculation, one study with stratified probabilistic sampling, proportionate to the mean number of children and adolescents attended six months prior to the study.

In relation to other degrees of parenthood, the mothers totaled the largest percentage of participation as caregivers, reaching up to $100 \%$ of the samples, in which the sample number varied between 15 and 787 caregivers.

The majority of the studies used transversal designs (20), followed by two longitudinal prospective designs. Quantitative, nonexperimental approaches predominated (21) and one classification as mixed research; two cohort studies were identified. The scientific evidence was shown to be at level IV (20) and at level III2 (two), respectively, in descriptive and cohort studies.

All the articles made use of descriptive statistics in generalization of the sociodemographic results, of burden and quality of life, with broad application of the SPSS (Statistical Package for the Social Sciences) in the statistical treatment of the data. In order to examine the influences on the caregivers' quality of life, the main statistical resources adopted were simple and multiple linear regression analyses; for determining the relationships between the various variables, the Pearson correlation coefficients were used; the comparison between the caregivers of different groups of children was undertaken using variance analysis (ANOVA), the Student t-test, and the Chi-squared test. For the statistical verification of the relationships existing between the variables, four studies used nonparametric correlation (the Spearman correlation coefficient, the Kruskal Wallis test, and the Wilcoxon test).

For the evaluation of burden of the mothers who were caregivers, general measurement instruments were used, tested in samples of caregivers caring for adults. The Zarit Burden Interview burden scale was applied in seven studies in the evaluation of burden of female caregivers of children and adolescents with sickle cell anemia, hemophilia, inborn errors of metabolism and cancer.

The Montgomery-Borgatta Caregiver Burden ScaleRevised was identified in a single investigation.

In relation to the instruments for evaluating quality of life of mothers who were caregivers for children or adolescents with chronic illnesses, applied in this sample of studies, emphasis was placed on the The World Health Organization Quality of Life-BREF (WHOQOLBREF Scale) in nine studies, used in the United States of America, Spain, and various states of Brazil; the SF-36 (Medical Outcomes Study 36-Item Short-Form Health Survey) in six studies; The UIm Quality of Life Inventory for Parents of chronically ill children in one article; the Pediatric Asthma Caregivers Quality of Life in two studies; and one investigation selected the Nottingham Health Profile.

Quality of life appears to be influenced in a complex and interrelated way by physical and mental health of the mothers who provide care, in accordance with their level of independence, the social relationships which they establish, the environment in which they live and the extent to which they perceive themselves as burdened.

The existence of the caregiver's burden, as one of the impacts of the chronic illness of the child or of the adolescent, is strongly evidenced in the literature, being compromised in various domains. The studies exposed the increase in the burden, when related to sociodemographic, physical and mental variables, such as the absence of a partner, a low educational level, mothers of mixed African and European descent, with insufficient income, unemployed, or with changes in their professional lives, reduction in social co-existence, with a higher number of children, the presence and degree of signs and symptoms of depression and anxiety, and raised tension in daily life. 
The perception of the seriousness of the pathology, sleepless nights or nights with interrupted sleep due to the acute manifestations of the illness, and disappointment in not being able to meet the children's needs, are also relevant factors for burden.

The most powerful predictors for poor quality of life were reported by the mothers, these being mainly the time spent asleep - which was below what they needed little or no perception of self-efficacy for the care of the ill child, lack of perceived social support, limitations of the maternal role, little vitality, mental health affected by high levels of depression and anxiety, functional compromise, low coping capacity, non-adaptation to the situation of chronic illness in the family, and care burden.

\section{Discussion}

\section{Methodological characteristics and their levels of evidence}

The quantitative, descriptive and nonexperimental studies were suited to the proposal of investigating the variables which may not be subjected to scientific control, in spite of the lack of control regarding the variables which are not in the study ${ }^{(19)}$. Even when the result demonstrates a positive correlation between the variable of quality of sleep and poor quality of life of the mother(20), a hidden variable may be responsible for the effect which has such an influence on both the quality of sleep and the quality of life, and which is not investigated - such as drinking alcohol, smoking, or the menopause.

The methods of sampling used were, mainly, convenience, possibly conferring some discordance in relation to the mothers who did not participate in the study, incurring the possibility of biases, as the price of convenience is the risk of divergences ${ }^{(19)}$.

Only two articles had a sample number below 30 individuals(21-22).

Regarding the time dimension in the outline of the studies, the transversal studies did not allow, in some results, the determination of causal associations between the variables examined, hiding the influence of other relevant variables, such as the presence of behavioral or cognitive problems in the child, influencing the mother's coping and self-efficacy ${ }^{(23)}$, and limiting, in this way, the planning of specific interventions.

On the other hand, longitudinal prospective studies, or those which require various meetings with the participants, can become nonviable, due to the researchers' lack of time and/or the high financial cost which may be expended(19).

The strength of the evidence presented in the levels III2 and IV is consistent with the studies reviewed, and strengthens the recommendations of the best studies for application in the professional practice ${ }^{(19)}$, mainly relating to the choice of the evaluation instruments and the proposals for intervention for minimization of the high scores of care burden and perception of low quality of life.

\section{Instruments for evaluating burden and quality of life used in the studies}

The population investigated, the objective of the study, and the availability of the instrument - adapted and validated for the language of interest - was decisive for defining the instrument for evaluating burden and quality of life which was most appropriate for each study.

The variable of caregivers' burden was evaluated using nonstandardized instruments for caregivers of children(20), possibly resulting in biases. The results may be influenced, due to the subjective character of the responses, which require of the mother who is a caregiver a certain precision and acceptance to explain the feeling that her children are burdens or causes for her physical and/or mental problems.

The Montgomery-Borgatta Caregiver Burden ScaleRevised(24) instrument has demonstrated good reliability in the evaluation of caregivers of adults and was used, for the first time, for evaluating burden of caregivers of children with chronic illnesses(20).

In relation to the SF-36(16), its suitability to the socioeconomic and cultural conditions of the Brazilian population, as well as its reproducibility and validity, made the instrument useful in evaluating various pathologies(25-27). In this review, the most affected domains were the emotional aspects and mental health, physical aspects, pain, vitality and social $\operatorname{aspects}^{(25-26,28-29)}$.

The UIm Quality of Life Inventory ${ }^{(30)}$, of German origin, had not yet been validated for other languages. It is an instrument for evaluating the quality of life of the mother and father of children with different chronic illnesses.

It is made up of 29 items, encompassed in the physical dimensions, daily functioning, satisfaction with the situation in the family, emotional suffering, selfdevelopment and well-being. The responses are given in relation to the previous week, on five-point scales, 
which vary from $0=$ never to $4=$ always. It was used to evaluate the quality of life of the parents of children and adolescents with phenylketonuria and to identify possible predictors of quality of life ${ }^{(21)}$.

The Paediatric Asthma Caregiver Quality of Life Questionnaire (PACQLQ) is configured as a questionnaire for reporting the quality of life of the caregiver ${ }^{(31)}$, with a scale made up of four items, which reflect how the child's asthma can affect sleep, the caregiver's work, and the family's experiences. The responses are given on a scale of seven points, where 1 represents severe impairment and 7 represents no impairment. The mean of all the items is the total score, in which higher scores indicate better quality of life.

The indicators of the caregiver's morbidity were investigated and the ethnic and regional differences in quality of life were determined, using the Paediatric Asthma Caregiver Quality of Life Questionnaire, in samples of female caregivers of children with asthma(32).

The Nottingham Health Profile evaluates the subjective perception of the physical, emotional and social aspects of health. The dimensions of health evaluated are energy, pain, physical mobility, emotional reactions, sleep, and social isolation. The mothers respond to the questions with "yes" or "no" and a higher score indicates a worse quality of life ${ }^{(33)}$.

The relations between maternal depression and quality of life were evaluated among female caregivers of children with neuromuscular disorders( ${ }^{(34)}$, in the Turkish version of the Nottingham Health Profile ${ }^{(33)}$.

\section{Quality of life of mothers who are caregivers in the light of the child's chronic condition}

The grandmothers ${ }^{(35)}$, fathers ${ }^{(28,36-37)}$ and other women ${ }^{(38)}$ of the family were shown to be linked to the activities of care, but the mothers remain the principal persons involved in the care process, constituting the absolute majority in all the studies highlighted(2-3).

The increase in the burden, related to sociodemographic variables and health variables is found in nearly all the articles, to the extent that the adverse conditions for dealing with the weaknesses imposed by the chronic illness are determinants for burden and worsening of quality of life ${ }^{(2,11)}$. Until public policies specifically focusing on female caregivers are put in place, identifying the risk factors for their health, this group's quality of life will continue to be affected ${ }^{(12,39)}$.

The literature indicates that the chronic illness of the children is associated with conjugal suffering, which can affect the adaptation to the care of the child and of siblings ${ }^{(4)}$. In some records, the mothers state that their conflicts with their spouse entail a risk factor for burden(21-22,26,36-38), which may be associated with the severity and frequency of the acute episodes of the illness, the quality of the care received and the caregivers' degree of knowledge ${ }^{(40)}$, as - due to not understanding the illness and not having access to coping strategies - these result in a greater incidence of marital disharmony ${ }^{(4)}$.

The quality of sleep among mothers ${ }^{(20)}$, besides relaxation and rest, seems to be affected in similar studies. When the various pathologies are compared, one can observe that the quality of sleep is always compromised, principally at times of $\operatorname{crisis}^{(10,14)}$.

It may be perceived that there is a certain variability in the mothers' adaptation to their children's chronic conditions, given that the majority feel themselves to be vulnerable, requiring support in various instances ${ }^{(21,36-38)}$. The improvement in the child's clinical quality does not mean, without exception, improvement in the mother's quality of life, as after 10 months of rehabilitation and significant improvement in the children's gross motor function, the mothers present significant improvement in the domain of bodily pain, but without improving the quality of life affected ${ }^{(29)}$.

The caregivers' quality of life scores tend to vary in accordance with the content of the information received(41), specific aspects of each illness ${ }^{(39)}$ and the personal resources of the caregivers. In the perception of absence of maternal self-efficacy, low levels of quality of life and mental health are established(23).

Mothers of children with mental and neurological compromise have high scores for burden and low quality of life $\mathrm{e}^{(21,29,34,38,42)}$, contrasting with the study of parents of children with cerebral palsy, whose perception of quality of life resembles that of parents of children without disabilities, challenging the pessimistic social and professional perspective, which tends to underestimate the families' potential for adaptation ${ }^{(9)}$.

The cultural beliefs and prejudices regarding these disabilities can mean greater vulnerability and difficulty for the parents, in thr experiencing of the positive perceptions regarding their lives and parenting ${ }^{(9)}$. In one investigation comparing quality of life of mothers of autistic and healthy children(12), there was no significant difference in the domains of quality of life between the caregivers, although the former classified their health as bad and tending to worsen. Additional problems in children with neurological and mental disorders are important targets for early intervention(13). 
Ethnic and regional differences and indicators of morbidity in samples of female caregivers of children with asthma - Latino and non-Latino - were determined in the evaluation of the quality of life ${ }^{(32)}$. Quality of life, in pediatric asthma, can be a reflection of the broader contextual stress which Latino female caregivers experience, due to cultural beliefs and acculturation ${ }^{(32)}$.

It is possible to distinguish in the findings the relevancy of social support networks, as the child's illness interferes directly in the daily life and in the female caregivers' social relationships(21-22,29,34,36,38,43). The help from a social support network, identification with a group, acceptance of one's own appearance and attribution of meaning to one's own life are important elements for overcoming adversity in the role of caregiver $^{(14)}$

Few studies reveal weak or moderate harm in the mothers' quality of life and burden(27,35,44), which showed that the greater the variable of length of time spent caring, the greater the satisfaction in relation to psychological well-being, the environment, and social relationships. The burden is not, however, always completely stated(23), denoting the need for further complementary studies, with objective evaluation tools.

\section{Conclusions and implications for the care}

This has implications for the planning and implementation of effective interventions, which may relieve burden, advancing the development of activities which involve the entire interdisciplinary team, facilitating the access to information, instrumentalizing the mothers for monitoring the child's condition, guaranteeing the treatment for the physical and psychological problems and offering support necessary for dealing with the challenges of caring for children and adolescents with chronic illnesses.

It is important to consider the mothers' conditions and sleep quality in the interdisciplinary evaluations, guiding them regarding the importance of rest for maintaining the care of their children at home at the highest level they can achieve.

It is important to encourage the caregivers' strong points and to promote meetings of groups of mothers, emphasizing the sense of empowerment for relieving feelings of impaired self-efficacy and consequent burden.

Complementary studies need to be used, emphasizing the needs of the mothers who are caregivers, their satisfaction with the treatment made available, difficulties met in accessing the specialized services, and support networks.
Burden and quality of life, associated with the various chronic illnesses not yet explored, are a field of investigation - in the perspective of the nurse - which needs to continue to advance. The continued application of burden scales in populations of female caregivers of children and adolescents will increase the reliability and validity of the instruments.

This review extended the support for decisionmaking regarding the necessary interventions for minimizing the impact of the chronic illnesses on the health and quality of life of the mothers who are caregivers.

\section{Limitations of the study}

It is sensible to recognize that the conclusions cannot be broadly generalized, as the articles recovered in this integrative literature review listed investigations, in the majority of which the evidence was established at level IV. These are considered less robust and lacking methodological strategies which consider the summarizing of the best scientific evidence, that is, that originating from systematic reviews or randomized clinical trials.

The less powerful hierarchies, however, seem to have been appropriate for the studies, involving evaluation of burden and quality of life.

\section{References}

1. Torres IEF, Prieto AM, Lían AH, Massa ER. Afectación de los bienestares en cuidadores de niños y adultos con enfermedad crónica. Rev Salud Pública. 2010 Oct; 12(5): 754-64.

2. Rehm RS. Nursing's contribution to research about parenting children with complex chronic conditions: An integrative review, 2002 to 2012. Nurs Outlook. 2013;61:266-90.

3. Borsa JC, Nunes MLT. Aspectos psicossociais da parentalidade: o papel de homens e mulheres na família nuclear. Psicol Argum. [Internet]. Jan/Mar 2011[acesso 2 dez 2013].;29(64). Disponível em: http://www2. pucpr.br/reol/index.php/pa?dd1=12626\&dd99=view 4. Brown BJ, Okereke JO, Lagunju IA, Orimadegun AE, Ohaeri JU, Akinyinka OO. Burden of health-care of carers of children with sickle cell disease in Nigeria. Health Soc Care Community. 2010;18(3):289-95.

5. Deeken JF; Taylor KL; Mangan P, Yabroff KR, Ingham JM. Care for the caregivers: a review of self-report instruments developed to measure the burden, needs, 
and quality of life of informal caregivers. J Pain Symptom Manage. 2003 Oct;26(4):922-53.

6. Medeiros MMC; Ferraz MB; Quaresma MR; Menezes AP. Adaptação ao contexto cultural brasileiro e validação do "Caregiver Burden scale". Rev Bras Reumatol. 1998 jul-ago;38(4):193-9.

7. Scazufca M. Brazilian version of the Burden interview scale for the assessment of burden of care in carers of people with mental illnesses. Rev Bras Psiquiatr. 2002;24:12-7.

8. The WHOQOL Group. The World Health Organization Quality Of Life Assessment. Position Paper From The World Health Organization. Soc Sci Med. nov 1995;41(10): 1403-9.

9. Carona C, Pereira M, Moreira H, Silva NM, Canavarro C. The Disability Paradox Revisited: Quality of Life and Family Caregiving in Pediatric Cerebral Palsy. J Child Fam Stud. 2013;22:971-86.

10. Favero-Nunes MA, Santos MA. Depression and Quality of Life in Mothers of children with Pervasive Developmental Disorders. Rev. Latino Am. Enfermagem. 2010;18(1):33-40.

11. Feijó FM, Carraro DF, Cuervo MRM, Hagen MEK, Spiandorello WP, Pizzato AC. Associação entre a qualidade de vida das mães e o estado nutricional de seus filhos. Rev Bras Epidemiol. 2011 Dec;14(4):633-41.

12. Kheir N, Ghoneim O, Sandridge AL, Al-Ismail M, Hayder S, Al-Rawi F. Quality of life of caregivers of children with autism in Qatar. Autism. 2012;16(3):293-8. 13. Estes A, Olson E, Sullivan K, Greenson J, Winter J, Dawson G et al. Parenting-related stress and psychological distress in mothers of toddlers with autism spectrum disorders. Brain Dev. 2013 Feb;35(2):133-8.

14. Zerbeto $A B$, Chun RYS. Qualidade de vida de cuidadores de crianças e adolescentes com distúrbios de fala e linguagem. CoDAS. [Internet]. 2013 [acesso 26 fev 2014];25(2). Disponível em: http:// www.scielo.br/scielo.php?script $=$ sci_arttext\&pid =S2317-17822013000200007

15. Fleck MPA, Louzada S, Xavier M, Chachamovich E, Vieira G, Santos L, et al . Aplicação da versão em português do instrumento abreviado de avaliação da qualidade de vida "WHOQOL-bref". Rev Saúde Pública. Abr 2000;34(2):178-83.

16. Ciconelli RM, Ferraz MB, Santos W, Meinão I, Quaresma MR. Tradução para a língua portuguesa e validação do questionário genérico de avaliação de qualidade de vida SF-36 (Brasil SF-36). Rev Bras Reumatol. mai/jun 1999;39(3):143-50.
17. Mendes KDS, Silveira RCCP, Galvão CM. Revisão integrativa: método de pesquisa para a incorporação de evidências na saúde e na enfermagem. Texto Contexto Enferm. 2008; 17(4):758-64.

18. Karino ME, Felli VEA. Enfermagem baseada em evidências: avanços e inovações em revisões sistemáticas. Cienc Cuid Saúde. 2012;1(supl):11-5.P14. 19. Polit DF, Beck CT. Fundamentos de pesquisa em Enfermagem: avaliação de evidências para a prática de enfermagem. $7^{a}$ ed. Porto Alegre: Artmed; 2011. p. 669.

20. Feeley CA, Turner-Henson A, Christian BJ, Avis KT, Heaton K, Lozano D, et al. Sleep Quality, Stress, Caregiver Burden, and Quality Of Life in Maternal Caregivers of Young Children With Bronchopulmonary Dysplasia. J Pediatr Nurs. 2014 Jan-Feb;29(1):29-38.

21. Miura RT, Petean EBL. Paralisia cerebral grave: o impacto na qualidade de vida de mães cuidadoras. Adv Health Psychol. [Internet]. dez 2012 [acesso 15 jan 2014];20(1-2):7-12. Disponível em: https://www. metodista.br/revistas/revistas-ims/index.php/MUD/ article/view/3146/3126

22. Pontes-Fernandes AC, Petean EBL. Sobrecarga Emocional e Qualidade de Vida em Mães de Crianças com Erros Inatos do Metabolismo. Psic Teor Pesq. outdez 2011;27(4):459-65.

23. Guillamón N, Nieto R, Pousada M, Redolar D, Muñoz $E$, Hernández $E$, et al. Quality of life and mental health among parents of children with cerebral palsy: the influence of self-efficacy and coping strategies. J Clin Nurs. 2013 Jun;22(11-12):1579-90.

24. Savundranayagam MY, Montgomery RJV, Kosloski K. A dimensional analysis of caregiver burden among spouses and adult children. Gerontologist. 2010;41:111.

25. Espírito Santo EAR, Marcon SR, Belasco AGS, Gaíva MAM, Espinosa MM. Taking care of children with cancer: evaluation of the caregivers' burden and quality of life. Rev. Latino- Am. Enfermagem. 2011;19(3):515.

26. Valença MP, Menezes TA, Calado AA, Cavalcanti GA. Burden and quality of life among caregivers of children and adolescents with meningomyelocele: measuring the relationship to anxiety and depression. Spinal Cord. 2012 Jul;50(7):553-7.

27. Melo TR, Jansen AK, Pinto RMC, Morales RR, Morales NM, Prado MM, et al. Qualidade de vida de cuidadores de crianças e adolescentes com sobrepeso ou obesidade. Rev Esc Enferm USP. 2011;45(2):319-26.

28. Lindvall K, von Mackensen S, Elmståhl S, Khair K, Stain AM, Ljung $R$, et al. Increased burden on caregivers 
of having a child with haemophilia complicated by inhibitors. Pediatr Blood Cancer. [Internet]. 2014 [acesso 22 abr 2014]. Apr;61(4):706-11. Disponível em: http://www.ncbi.nlm.nih.gov/pubmed/24277475

29. Prudente COM, Barbosa MA, Porto CC. Relation Between Quality of Life of Mothers of Children With Cerebral Palsy and the Children's Motor Functioning, After Ten Months of Rehabilitation. Rev. Latino- Am. Enfermagem. 2010 Apr;18(2):149-55.

30. Goldbeck L, Storck M. Das Ulmer LebensqualitätsInventar für Eltern chronisch kranker Kinder (ULQIE): Entwicklung und psychometrische Eigenschaften. [ULQIE: A quality-of-life inventory for parents of chronically ill children.] Z Klin Psychol Psychother. 2002;11:31-39.

31. Juniper, E.F.; Guyatt, G.H.; Feeny, D.H. Ferrie PJ, Griffith LE, Townsend M. Measuring quality of life in the parents of children with asthma. Qual Life Res. 1996;5:27-34.

32. Everhart RS, Koinis-Mitchell D, McQuaid EL, Kopel S, Seifer R, Canino G, Fritz G. Ethnic differences in caregiver quality of life in pediatric asthma. J Dev Behav Pediatr. 2012 Oct;33(8):599-607.

33. Küçükdeveci A, McKenna SP, Kutlay S, Gursel Y, Whalley $D$, Arasil T. The development and psychometric assessment of the Turkish version of the Nottingham Health Profile. Int J Rehabil Res. 2000;23:31-8.

34. Yilmaz O, Yildirim SA, Oksüz C, Atay S, Turan E. Mothers' depression and health-related quality of life in neuromuscular diseases: role of functional independence level of the children. Pediatr Int. 2010 Aug;52(4):64852.

35. Nóbrega KIM, Pereira CU. Quality of life, anxiety and depression in children caregivers with brain neoplasm. Psicol Teor Prát. 2011;13(1):48-61.

36. Fidika A, Salewski C, Goldbeck L. Quality of life among parents of children with phenylketonuria (PKU). Health Qual Life Outcomes.[Internet]. 2013[acesso 12 jan 2014]. Mar;28(11):54. Disponível em: http://www. ncbi.nlm.nih.gov/pubmed/23537423

37. Martín J, Padierna A, Aguirre U, González N, Muñoz P, Quintana JM. Predictors of quality of life and caregiver burden among maternal and paternal caregivers of patients with eating disorders. Psychiatry Res. 2013 Dec 30;210(3):1107-15.

38. Khanna R, Madhavan SS, Smith MJ, Patrick JH, Tworek C, Becker-Cottrill B. Assessment of healthrelated quality of life among primary caregivers of children with autism spectrum disorders. J Autism Dev Disord. 2011 Sep;41(9):1214-27.
39. Flórez-Torres IE, Montalvo-Prieto A, Herrera-Lían A, Romero-Massa E. Afectación de los bienestares en cuidadores de niños y adultos con enfermedad crônica. Rev Salud Pública. Oct 2010;12(5):754-64.

40. Bellin $M H$, Kub J, Frick KD, Bollinger ME, Tsoukleris $M$, Walker J, et al. Stress and quality of life in caregivers of inner-city minority children with poorly controlled asthma. J Pediatr Health Care. 2013 MarApr;27(2):127-34.

41. Kim KR, Lee E, Namkoong K, Lee YM, Lee JS, Kim HD. Caregiver's burden and quality of life in mitochondrial disease. Pediatr Neurol. 2010 Apr;42(4):271-6.

42. Cadman T, Eklund H, Howley D, Hayward $H$, Clarke $H$, Findon J, et al. Caregiver burden as people with autism spectrum disorder and attention-deficit/hyperactivity disorder transition into adolescence and adulthood in the United Kingdom. J Am Acad Child Adolesc Psychiatry. 2012 Sep;51(9):879-88.

43. Carvalho JTM, Rodrigues N M, Silva LVC, Oliveira DA. Qualidade de vida das mães de crianças e adolescentes com paralisia cerebral. Fisioter Mov. 2010 Sep;23(3):389-97.

44. Silva LBL, Ivo ML, Souza AS, Pontes ERJC, Pinto AMAC, Araujo OMR. The burden and quality of life of caregivers of sickle cell anemia patients taking hydroxyurea versus those not taking hydroxyurea. Rev Bras Hematol Hemoter. 2012;34(4):270-4. 